\title{
LA RECUPERACIÓN DEL ALCÁZAR DE SEVILLA. UN ELEMENTO DE TENSIÓN ENTRE LOS REYES CATÓLICOS Y LA CIUDAD DE SEVILLA.*
}

\author{
THE RECOVERY OF THE ALCAZAR OF SEVILLE. \\ AN ELEMENT OF TENSION BETWEEN THE CATHOLIC KINGS \\ AND THE CITY OF SEVILLE. \\ À RECUPERAÇÃO DOS REAIS ALCÁZARES DE SEVILHA. \\ UM ELEMENTO DE TENSÃO ENTRE OS REIS CATÓLICOS \\ E A CIDADE DE SEVILHA.
}

\author{
ALBERTO TREJO MARTÍN** \\ Instituto Nacional de Estudios Históricos \\ sobre las Revoluciones de México
}

DOI: https://doi.org/10.46553/EHE.22.1.2020.p20-34

\begin{abstract}
Resumen
Este trabajo aborda las múltiples tensiones y conflictos que existieron entre los Reyes Católicos y el concejo de Sevilla alrededor de los Reales Alcázares de Sevilla y las prerrogativas o privilegios que ese lugar y sus oficiales tenían como propios. Estos pleitos, que son paralelos a la recuperación material y simbólica del palacio operada durante su reinado, abarcaron elementos fundamentales para la vida de la sociedad sevillana, como lo eran el aprovisionamiento y la administración del agua de la urbe o la distribución de las contribuciones debidas por los sevillanos. Las disputas abordadas muestran las dificultades que el proyecto de recuperación de la residencia regia conllevó, la importancia que tuvieron los oficiales del palacio como mediadores, así como la problemática relación entre el Alcázar y la ciudad.
\end{abstract}

\section{Palabras clave}

Sevilla - Alcázar de Sevilla - Reyes Católicos - concejo sevillano - conflicto de jurisdicciones.

\begin{abstract}
This article presents the multiple tensions and conflicts that existed between the Catholic Kings and the town council of Seville regarding the rights and prerogatives owed to the royal palace of Seville and its officials. The disputes, which occurred while the Alcazar was being restored to make it an important place for the Monarchy, involved many areas which were fundamental for the Sevillian society, for example, the administration and distribution of water in the city or how the taxes and contributions were shared by the inhabitants of the city. These conflicts show the difficulties that the recuperation of the palace entailed, the important role that the palace officials played as intermediaries and the complex relation established by the town with the royal site.

\footnotetext{
${ }^{*}$ Fecha de recepción del artículo: 6/6/19. Fecha de aceptación: 16/3/2020.

** Jefe de departamento del Instituto Nacional de Estudios Históricos de las Revoluciones de México (INEHRM). Número de ORCID: 0000-0002-4135-1056. Dirección Postal: Dr. R. Cervantes Ahumada 21 CP. 01710, Ciudad de México, México, E-mail: albertotm9@ hotmail.com.
} 


\section{Key words}

Seville - Alcazar of Seville - Catholic Kings - Sevilla's town council - conflict of jurisdictions.

\section{Resumo}

Este trabalho trata das múltiples tensões e conflitos que existiram entre os Reis Católicos e o conselho municipal de Sevilha acerca dos Reais Alcázares de Sevilha e as prerogativas ou privilegios que esse lugar e seus oficiais tinham como proprios. Estes litígios, que são paralelos à recuperação material e simbólica do palacio realizada durante seu reinado, incluiram elementos fundamentais para a vida da sociedade sevilhana, como o eram o abastecimento e administração da agua da cidade ou a distribuição das contribuições devidas pelos sevilhanos. As disputas abordadas mostram as dificuldades que o projeto de recuperação da residencia real envolveu, a importância que tiveram os oficiais do palacio como intermediários, assim como a problemática relação entre o Alcázar e a cidade.

\section{Palavras chave}

Sevilha - Alcázar de Sevilha - Reis católicos - administração da agua - conflito de jurisdições

El 28 de julio de 1477 Isabel I de Castilla ingresó por primera vez a la ciudad de Sevilla, ciudad que no había sido visitada por un rey castellano en poco más de diez años. Tras una larga ceremonia de entrada que la llevó de la puerta de la Macarena a la catedral, la monarca tomó posesión de los Reales Alcázares, que habían estado bajo el cuidado del duque de Medina Sidonia. Sin embargo, a juzgar por las capitulaciones hechas entre el obrero mayor del palacio, Francisco Ramírez de Madrid, y la soberana castellana un año después, ${ }^{1}$ el estado del conjunto edilicio era bastante deplorable. ${ }^{2}$

Frente a esta situación, la nueva monarca decidió apostar por una serie de intervenciones y de medidas que tenían por objetivo la recuperación material y funcional del sitio. Esta operación era fundamental si querían hacerlo nuevamente un escenario privilegiado donde la Monarquía pudiera hacerse visible, presentarse a los miembros del reino y gobernar sobre una ciudad que desde mediados del siglo XV se estaba convirtiendo en el nodo central del creciente comercio atlántico.

Si bien el proceso arriba mencionado ya ha sido analizado por otros investigadores, ${ }^{3}$ una revisión de variada documentación de la época ha permitido observar un ámbito de esta recuperación que no ha sido profundamente abordado por esas investigaciones, me refiero a la defensa de ciertos derechos y prerrogativas pertenecientes al sitio real que se llevó a cabo en este periodo.

A través de los documentos trabajados se puede apreciar que un problema con el que se encontraron los Reyes Católicos y sus oficiales fue que a lo largo de todo el siglo

\footnotetext{
${ }^{1}$ AGS, Escribanía Mayor de Rentas, Tenencia de Fortalezas, 4.

${ }^{2}$ Esta situación, se repetía en varios palacios y fortalezas reales de la región andaluza, por lo que en varios de ellos se llevaron a cabo intervenciones similares de recuperación, vid CASTILLO OREJA, 2001, p. 99-128.

${ }^{3}$ Se pueden citar las investigaciones de: GESTOSO, 1891; MARÍN FIDALGO, 1990, vol. 1; DOMÍNGUEZ CASAS, 1993; ALMAGRO GORBEA, 2007, p. 155-185; MORALES, y SERRERA, 1999, pp. 69-77; LADERO QUESADA, 2001, p.11-35; MORALES, 2001, p.129-144; MORALES, 2011, p. 35-48; ALMAGRO GORBEA, 2015, pp. 69-115; FERNÁNDEZ AGUILERA, 2015, p.331-348.
} 
$\mathrm{XV}$, los habitantes y el gobierno de la urbe dejaron de respetar los privilegios que la residencia real debía gozar.

Así pues, en las próximas páginas se abordarán las negociaciones y los pleitos que los oficiales de la corte regia castellana llevaron a cabo respecto al derecho sobre el agua que alimentaba las fuentes, los jardines, las cocinas y las huertas del complejo palaciego, los privilegios de los artesanos y trabajadores encargados de realizar las obras, o los ingresos monetarios del sitio real con los que se pagaban los salarios y obras materiales.

Con esta investigación se espera contribuir al entendimiento de la relación que se estableció entre la urbe y la residencia regia, así como el significado de esta última en las dinámicas sociales y políticas de la ciudad.

Para finalizar, es importante señalar que los pleitos y conflictos que a continuación serán presentados fueron encontrados en documentos provenientes de los ramos Registro del Sello de Corte y Cámara de Castilla en el Archivo General de Simancas, así como del Tumbo de los Reyes Católicos de la ciudad de Sevilla. La mayoría de las fuentes consultadas fueron producidas desde el ámbito regio y, por lo mismo, transmiten principalmente una perspectiva regiocéntrica, por lo que será conveniente tener presente este aspecto durante su análisis.

\section{Los trabajadores del palacio}

Un elemento central para operar la recuperación y mantenimiento del palacio que los Reyes Católicos deseaban eran los francos del Alcázar; trabajadores adscritos al sitio que se encargaban de las tareas de albañilería, carpintería, yesería, herrería o horticultura que el complejo palaciego requería, además de vigilarlo, toda vez que no había una guardia armada asignada a él.

Al igual que otros grupos de francos, los trabajadores de la residencia regia gozaron de ciertas franquezas y exenciones, las cuales son enumeradas en una carta del año de 1479:

"son quitos e francos e esentos de los dichos pedidos e monedas e moneda forera e de todos los otros pechos e tributos e serviçios e derramas e enprésitos, así reales como conçegiles, e que non sean maheridos para ser cojedores, ni enpadronadores, ni repartidores dellos, ni para guías e rondas e lieuas de pan e otros basteçimientos para los reales e huestes e castillos fronteros, e de yr en guerra ni en hueste ni en asonada, ni en apellido, ni con el pendón de la çibdad, e de todo aposentamiento de huéspedes." ${ }^{4}$

Como se puede observar, estos privilegios les eximían de varias cargas y contribuciones que debían aportar los vecinos sevillanos. La razón de esta situación era la baja la remuneración que recibían, puesto que su salario solía ser menor que el de un trabajador de la ciudad. ${ }^{5}$ Bajo la misma idea, para mantener su calidad de trabajadores francos, su cantidad de bienes debía mantenerse dentro de cierto rango, por ejemplo, en 1471 el límite era de 10,000 mrs. $^{6}$

\footnotetext{
4 "Carta sobre lo de los francos de las atarazanas e alcázares, que les guarden los privilegios." CARRIAZO ARROQUIA, y CARANDE (eds.), 1968, Tomo II, p. 363-364.

${ }^{5}$ COLLANTES DE TERÁN SÁNCHEZ, 1984, p. 237.

${ }^{6}$ COLLANTES, op cit, p. 238-239.
} 
No obstante, a decir de las autoridades de la ciudad, no todos los que gozaban de ese régimen de exenciones respetaban el límite económico. Para los miembros de la sociedad sevillana esto resultaba una injusticia, dado que debían soportar una mayor carga en la repartición de contribuciones, así como un prejuicio para el gobierno concejil, que no podía cumplir con sus obligaciones frente a la Corona. Con estos argumentos fue que el concejo hispalense presionó durante el siglo XV para que se redujera el número total de francos del palacio y de las atarazanas. A esto tuvieron que hacer frente Isabel I de Castilla y Fernando II de Aragón a lo largo de su reinado.

La primera muestra de esa disputa la representa una carta enviada por los monarcas con fecha del 26 de julio de 1479, momento en el que se estaban llevando a cabo una importante serie de obras de reparación en el sitio real. La misiva, que iba dirigida al asistente en Sevilla y a los demás miembros del gobierno municipal, señala que Pedro de Silva, maestresala de la Reina y alcaide del sitio real, había informado que en esas fechas se estaba obligando a los francos a participar en los pechos, así como a que mantuvieran caballos y armas para que pudieran participar en algún conflicto armado.

Frente a esto, la Corona argumentaba que los oficiales y maestros habían gozado del estatus de francos en otros reinados porque sus labores eran más redituables para la Corona y la ciudad que los requerimientos y contribuciones con los que cumplían el resto de los vecinos de la ciudad.

Las autoridades concejiles, por su cuenta, alegaban haber comenzado a cobrar las contribuciones porque "algunos dellos [francos] han creçido en sus cabdales e fasiendas después que tienen los dichos ofiçios e franquesas, e que agora son de la mayor contía"7, siendo que habían empezado en sus oficios durante los reinados de Juan II y Enrique IV, cuando todavía eran de menor o mediana cuantía.

La resolución de la soberana fue que del enriquecimiento de los obreros no se debería seguir que se volvieran pecheros. En el fondo de su razonamiento estaba su proyecto de recuperación del palacio, toda vez que cumplir con las cargas municipales implicaría la destrucción y daño de los palacios reales en Sevilla

"porque no se fallarían otros maestros ni ofiçiales de algunos de los ofiçios que ellos son en todos mis Regnos, porque non ay otros ofiçiales, que sopiesen servir enllos, e aunque los oviesen non querrían ninguno entrar a servir aviendoles de poner por condiçión que en tanto que los toviesen e siruiesen no creçiesen ni mejorasen sus faziendas." 8

Como ya se señaló antes, por esas fechas Francisco Ramírez de Madrid estaba dirigiendo las reparaciones que urgían en el palacio para volver a hacerlo funcional.

Así pues, la carta exigía que respetaran los privilegios, so pena de pagar $2000 \mathrm{mrs}$. por cada vez que se incumpliera ese mandato, cantidad con la que se pagarían obras en los palacios, atarazanas o puertas de la ciudad. No deja de ser interesante que la misma reina señale en la carta la especialidad y maestría que tenían los trabajadores del sitio real

\footnotetext{
7 "Carta sobre lo de los francos de las atarazanas e alcazares, que les guarden los privilegios" en CARRIAZO ARROQUIA y CARANDE (eds.), op cit, Tomo II, p. 364.

${ }^{8}$ Ibídem.
} 
sevillano, aspecto que los haría casi imposible de reemplazar, más aún si se tiene en cuenta que era común que se heredara el oficio a los hijos. ${ }^{9}$

Como resultado de esta llamada de atención, Pedro de Silva y el gobierno municipal llegaron a un acuerdo. En él establecían que se reduciría la cantidad de francos en las atarazanas y el palacio, quedando por asentados

"dosientos e setenta e cinco francos, para que siruieran en los dichos sus ofiçios e les fuesen guardadas las dichas sus franquesas, e que les fuesen tornados e restituydas qualesquier prendas que les auían seydo tomadas por los dichos pechos e seruiçios, e qualesquier maravedís que dello auían pagado e prestado."10

Mientras que el resto de los puestos que quedaran vacantes, hasta llegar a los 400 francos de las Atarazanas y los 36 de los Alcázares, serían nuevamente nombrados por el alcaide con la limitante de tener que respetar el límite en la hacienda impuesto, ${ }^{11}$ esto con la intención de que el concejo pudiera recibir las contribuciones correspondientes.

Medio año después de haber enviado la carta al gobierno municipal de Sevilla, Isabel I volvió a enviar una misiva. en la que reclamaba que las autoridades concejiles acataran el acuerdo al que habían llegado con Pedro de Silva. La soberana ordenaba que les devolvieran a los 275 trabajadores francos asentados los maravedís que habían pagado o prestado a la ciudad para que esta hiciera frente a los pagos por la guerra, puesto que la situación estaba repercutiendo en el cuidado de los palacios y las Atarazanas: "por esta cabsa dis que non quieren faser en las dichas casas los seruiçios de que por razón de las dichas esençiones deuen e son tenidos de faser." 12

El texto, además, menciona el caso de tres individuos, Catalina Sanches, ortelana de la Huerta de Alcoba, Garçi Gonçales de Talauera, cosedor de velas de las atarazanas y Gonçalo Fernandes, latonero, de las atarazanas, quienes no habían sido contados como francos ya que los miembros del ayuntamiento consideraban que sus cuantías sobrepasaban los límites establecidos. La carta señala que los tres debían de ser considerados como tales. $^{13}$

El pleito reapareció una vez que se celebraron las Cortes de Toledo en mayo de 1480, puesto que en ellas se aprobó una ley que indicaba que aquellos exentos de tributos en las ciudades castellanas, como las viudas o los huérfanos, "non se entiendan ser ni sean escusados, en manera alguna, de los pechos e derramas conçejiles." ${ }^{4}$ Esta ley, que se podría haber entendido como una autorización para que el concejo cobrara contribuciones a los trabajadores francos rápidamente tuvo que ser atajada por los reyes. En una nueva misiva dirigida a las autoridades de Sevilla se les señala que dentro de esa normativa no debían ser incluidos los 400 francos de las atarazanas, ni los 36 de los Alcázares, quienes,

\footnotetext{
${ }^{9}$ Se conocen los casos de Mahomad Agudo y su hijo Hamete Agudo, ambos maestros mayores de albaliñeria, Francisco Fernández, nombre cristiano de Hamete Cobexí, y su hijo Juan Fernández; Juan de Limpias y su hijo Francisco de Limpias, ambos maestros mayores de carpintería. Vid DOMÍNGUEZ, op cit, p. 66-69.

10 "Carta que se guarde la conveniencia fecha con los francos de los alcázares y atarazanas." en CARRIAZO ARROQUIA y CARANDE (eds.), op cit, Tomo III, p. 62.

${ }^{11}$ Ibídem.

${ }^{12}$ Ibídem.

${ }^{13}$ Ibídem.

${ }^{14}$ Ley 103 de las “Ordenanzas de las Cortes de Toledo de 1480”, en Cortes de los antiguos reinos de León y Castilla, 1882, p. 181. También en "Carta que trajo Pedro de Silva sobre los francos del alcázar." en CARRIAZO ARROQUIA y CARANDE (eds.), op cit, Tomo III, p. 134.
} 
por gozar de sus franquezas y exenciones desde los reinados de los reyes anteriores, y por los servicios que desempeñaban para la Corona, debían de ser exentados. ${ }^{15}$

Tres años después volvuió a surgir el tema, ya en plena guerra con el reino nazarí. En una petición del concejo de Sevilla a los monarcas se puede encontrar el mismo argumento antes visto, había una gran cantidad de francos en la ciudad que se escudaban en su condición de tales para no tener que aportar en las cargas concejiles, a pesar de que estaban a mitad de un conflicto militar. E insistían que mientras los francos eran personas con bastante riqueza, las contribuciones recaían en los pobres de la ciudad, quienes no terminaban por cubrir todos los gastos, generando problemas en el desempeño de la guerra. $^{16}$

Enfrentada con esta situación, la reina Isabel señalaba que, "siendo una guerra santa, justa y necesaria", se debía presionar a los francos para que contribuyeran "en los dichos gastos e neçesidades de la dicha guerra, en los repartimentos e cosas que para ello fueren echados e se echaren de aquí adelante." ${ }^{17}$ Esta autorización no debía entenderse como la posibilidad de sobrepasar los privilegios de los francos y, algo llamativo, como último punto señala que estarían exentos de esto los francos de las "yglesias e monesterios", sin embargo, no se menciona a los que trabajaban en el sitio real. Esto es relevante ya que poco tiempo después encontramos comunicaciones de Fernando el Católico, en las cuáles indica la necesidad de exentar de los pechos a determinados obreros del sitio real ${ }^{18}$ que se hallaban realizando obras de reparación en los años de las misivas. ${ }^{19}$

La razón de por qué no incluir a los trabajadores del palacio la da el mismo rey en el documento referente al caso del maestro mayor de los pintores, Alfonso Ruiz. En ella encontramos un razonamiento similar al esgrimido en otra carta anterior:

"e porque algunos de los dichos francos son tan neçesarios e conplideros para los seruiçios e reparos que de continuo fasen en las dichas mis casas, non se pueden escusar algunos dellos que les sean guardados sus preuillegios e esençiones." ${ }^{20}$

Pareciera que en ningún momento se estaba pensando en incluir dentro de la posibilidad de exigir los pechos a los francos del palacio, cuyo trabajo era fundamental para

\footnotetext{
15 "Carta que trajo Pedro de Silva sobre los francos del alcázar", op. cit., p. 135.

16 "Carta que todos generalmente pechen" en CARRIAZO ARROQUIA y CARANDE (eds.), op cit, Tomo III, p. 307.

${ }^{17}$ Ibídem.

18 "Carta de franqueza de Juan de Limpias, maestro de las atarazanas, para que se le exente de los pechos, a pesar de la carta anterior del rey" en CARRIAZO ARROQUIA y CARANDE (eds.), op cit, Tomo III, p. 403; "Carta para que les guarden sus derechos y privillegios de moneda forera y cabeza de pecho, a los francos de los alcázares y atarazanas" en CARRIAZO ARROQUIA y CARANDE (eds.), op cit, Tomo III, p. 369; "Carta de franqueza a Alfonso Ruiz, maestro mayor de los pintores de los alcazares, para que le respeten sus franquezas, a pesar de la carta del rey donde pide que todos contribuyan a la guerra con el moro" en CARRIAZO ARROQUIA y CARANDE (eds.), op cit, Tomo III, p.402-403; "Carta de franqueza de Catalina Sánchez, hortelana de la Huerta de Alcoba, para que se le mantengan los derechos y exenciones como franco del alcázar", CARRIAZO ARROQUIA y CARANDE (eds.), op cit, Tomo III, p.506-507

19 "Documento 2. 1498, abril, 11. Alcalá de Henares. Los Reyes Católicos otorgan a su secretario Francisco Ramírez de Madrid carta de finiquito de las cuentas presentadas ante los contadores mayores sobre su gestión como obrero mayor de los Alcázares y Atarazanas de Sevilla (1478-1495)”, en FERNÁNDEZ GÓMEZ (ed.), op. cit., p. 116-120.

${ }^{20}$ Ibídem.
} 
que la residencia real sevillana pudiera fungir como lugar de la corte durante la confrontación con el reino nazarí.

Esta problemática sigue apareciendo en documentos del año de $1496,{ }^{21} 1499,{ }^{22}$ $1501,{ }^{23} 1502^{24}$ e incluso $1509,{ }^{25}$ este último ya durante el reinado de Juana I de Castilla. Particularmente interesante es el documento del año de 1502 con el que los reyes nombraron a Francisco Hernández, antes Hamete Cobexi, como maestro mayor de las obras de albañilería, otorgándole con ello todos los beneficios y franquezas que el puesto llevaba anexos, situación que debía ser acatada por el gobierno concejil. La orden fue recibida por el concejo, sin embargo, en un texto añadido a la carta, el jurado Romero señaló

"que los dichos ofiçios son acreçentados de más de los francos de los alcaçares e ataraçanas e non se devían reçibir e que requerían e pareçe que requirieron a los dichos teneniente e regidores que no lo reçibiesen e pidiéndolo por testimonio." 26

Tras lo cual se pidió su opinión a los letrados de la ciudad. Ellos señalaron que las cédulas emitidas por los monarcas en favor de Francisco Hernández debían ser acatadas si no excedían el número de francos permitidos.

El que un jurado, como supuesto representante del pueblo llano y por tanto de los pecheros, se opusiera al incremento de los francos más allá de las cuotas establecidas me parece que revela la tensión existente entre la sociedad sevillana y este cuerpo de individuos que tenían una carga impositiva diferente por el hecho de laborar en las casas de los monarcas. Como se puede ver, en este frente los Reyes Católicos debieron de defender y mantener las prerrogativas pertenecientes a los trabajadores del palacio, y con mayor razón dada la necesidad que tenían los monarcas de la labor de estos artesanos para recuperar materialmente su residencia real sevillana.

\section{Los ingresos del palacio y las contribuciones de la ciudad a ellos.}

Sin embargo, las exenciones y privilegios antes mencionados no eran las únicas cargas fiscales que conllevaba la presencia de la residencia regia en la ciudad, y por tanto, tampoco el único elemento en disputa entre la Corona y el concejo. Durante el siglo XV y el siglo XVI, el alcázar contó con una serie de propios, principalmente los diezmos provenientes de la producción de ladrillo, teja, cal y carbón de la ciudad. Una parte de los ingresos necesarios para pagar los salarios de los oficiales y los trabajadores, así como para conseguir los materiales necesarios para las obras provenía de dichos elementos. Por este motivo el alcaide del Alcázar, el Obrero Mayor y la corte real debieron estar atentos a esos recursos y defenderlos siempre que fuera necesario, puesto que no siempre eran respetados.

De lo aportado por los mencionados diezmos poseemos una fuente fundamental que ha sido ya analizada con profundidad por Alfredo J. Morales. ${ }^{27}$ Se trata de las cuentas entregadas por el obrero mayor de los Alcázares, en las que, además de abordar las distintas obras realizadas entre 1478 y 1495, se presenta un recuento de los ingresos que tuvo el

\footnotetext{
${ }^{21}$ GESTOSO, 1889-1890, Tomo I, p. 419-420.

${ }^{22}$ Ibídem, p. 420-421.

${ }^{23}$ Ibídem, p. 421-422.

${ }^{24}$ AGS, CCA, DIV, 42, 20, f. 100v.

${ }^{25}$ GESTOSO, op cit, p. 422-434.

${ }^{26}$ AGS, CCA, DIV, 42, 20, f. 100v.

${ }^{27}$ MORALES, op cit, p. 35-48
} 
alcázar provenientes de las contribuciones de la ciudad y de algunos otros elementos, como el arriendo de casas y tiendas ubicadas en el Alcázar viejo o ciertas partidas extraordinarias en años puntuales. Es importante señalar que todos los ingresos del palacio debían ser administrados y utilizados por el Obrero Mayor del Alcázar y el alcaide en común acuerdo.

Un examen de las cuentas antes mencionadas hace evidente que estas contribuciones eran fundamentales para el mantenimiento del complejo palaciego y el pago de salarios, en tanto que, a excepción de los años en que los reyes otorgaron cantidades extraordinarias para llevar a cabo determinadas obras de gran escala, ${ }^{28}$ aquellas contribuciones implicaban la mayoría del dinero que llegaba a manos del Obrero Mayor.

También es importante señalar que, de los diezmos ya mencionados, el de mayor valor era el del carbón, llegando a representar cantidades superiores a 150,000 mrs. en varios de los años registrados, mientras que la cantidad aportada en conjunto por los de la teja, el ladrillo y la cal solía ser menor a esa cifra.

Así pues, la importancia de estos ingresos en el marco de la recuperación del palacio ideada por los monarcas no era menor y, por tanto, la aparición de problemas en su recepción en los primeros años de su reinado tuvo que ser atendida por la corte real. Ya en julio de 1479 tenemos el primer caso, puesto que la reina debió enviar una carta a los vecinos de Sevilla para recordarles que, como parte de un derecho de tiempo inmemorial, la ciudad debía pagar un diezmo de toda la cal, teja y ladrillo que se produjera en los hornos de ella, lo cual estaría destinado a las reparaciones que los palacios requirieran. El fundamento era que:

"antiguamente no avia otros fornos de coser teja e ladrillo, salvo los fornos que los dichos mis alcaçares tenían en la vega de Triana. E que asy para consentir faser de nuevo los fornos que después se fisieron como por el barro e lenna realengo que para ellos se toma están en posisión e uso e costunbre de llevar el dicho diesmo e derecho". ${ }^{29}$

El problema era que de un tiempo a esa fecha habían sido construidos algunos hornos en la ciudad, principalmente por personas de la Iglesia, que se excusaban de pagarlo señalando que no eran parte de la jurisdicción real. Esto implicaba una pérdida para el patrimonio regio en tanto que esos recursos debían de ir a parar al pago del alcaide y de las obras de los palacios, que estaban en pleno desarrollo en ese año. Ante este panorama, Isabel ordenó a la gente de la ciudad que volviera a pagar el diezmo, so pena de que el oficial encargado del palacio hiciera las execuciones y pedimientos necesarios. ${ }^{30}$

Esta advertencia es reforzada en enero de 1480 con una sobrecarta dirigida específicamente a las personas eclesiásticas y a los del concejo, en la que los reyes repetían la obligación de pagar el diezmo de cal, ladrillo y teja, toda vez que a partir de ese diezmo o de su arriendo, es que "los dichos nuestros alcaçares e los grandes hedifiçios e obras dellos se fasen e reparan e se pagan la tenençia e raçiones e quitaçiones al nuestro alcayde e

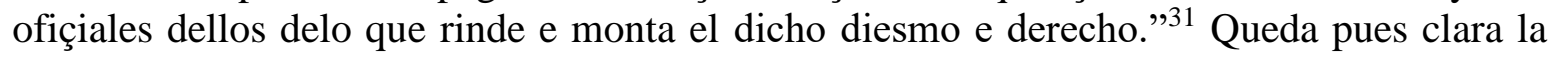
importancia de estas fuentes de ingresos en el proyecto de recuperación.

Ahora bien, es importante señalar que se introdujo una pequeña excepción dentro del mismo documento. Aunque los monarcas continuaban en la idea de que los hornos ya

\footnotetext{
${ }^{28}$ A saber, los años de 1483, 1484, 1486, 1488.

${ }^{29}$ AGS, RGS, LEG 147907, 122.

${ }^{30}$ Ibídem.

${ }^{31}$ AGS, RGS, LEG 148001, 136, f.2.
} 
construidos y por construir en la ciudad debían pagar su parte, aceptaban como excepciones el horno de la Iglesia Mayor y el del monasterio de las Cuevas, ya que en ambos casos se estaban realizando trabajos de construcción que requerían esos productos.

Los diezmos se encontraban arrendados a ciertas personas, quienes acordaban con las autoridades del palacio una cantidad a entregar por dicha concesión, lo que en las fuentes se llama "prometido". Éste podía implicar una ganancia o una pérdida para los arrendadores, situación que llegó a generar algunos problemas para las autoridades reales, sobre todo en los momentos en que el diezmo no podía ser cobrado, como fue el caso de Gómez de Córdoba, vecino de la ciudad, quien había arrendado el diezmo del ladrillo y la teja en los años de 1498 y 1499, pero que no pudo cobrarlo por completo debido a la negativa de algunos hornos a entregarle el diezmo. Esto generó que de la cantidad que debía pagar por el arriendo, le faltaran 30,000 mrs.

La negativa de los productores de ladrillo y teja a pagar la contribución tenía como fundamento una merced que por ese mismo periodo de tiempo habían otorgado los Reyes Católicos a la ciudad para que cuatro hornos estuvieran exentos de aportar el diezmo sobre su producción. La razón fue que a finales del siglo XV dio inicio una campaña de enladrillado de algunas calles de la urbe, con lo que se había incrementado la demanda de esa mercancía y, por lo tanto, la dificultad para cumplir con las obligaciones debidas a la residencia regia. ${ }^{32}$

Las continuas quejas de los propietarios de los hornos por la insistencia de Gómez de Córdoba hicieron que el cabildo de la ciudad escribiera a los monarcas para pedir que se respetara la exención que tenían. ${ }^{33}$ Frente a esto, la Corona decidió ordenar a Juan Ome, su lugarteniente del alcaide, y a Pedro de Maluenda, juez de las suplicaciones y término de Sevilla, para que dieran solución a la querella. Para esto debían determinar si los hornos que no habían querido pagar estaban incluidos en la merced. En caso de que no lo estuvieran, estos debían saldar la cantidad adeudada a Gómez de Córdoba, pero en caso de que sí lo estuvieran, Juan Ome le debería condonar los 30,000 mrs. de la renta al arrendador. ${ }^{34}$ Desafortunadamente no se encontró información sobre el desenlace de este pleito, sin embargo, sirve para mostrar los problemas que enfrentaron los reyes para defender una fuente de ingresos fundamental para poder operar su proyecto.

\section{La administración del agua y el palacio.}

La decisión de los monarcas de recuperar la dignidad del Alcázar sevillano también generó problemas entre el concejo y la Corona por un tercer elemento que interesaba a ambas instituciones, al agua que llegaba a la ciudad y que también alimentaba las estancias palaciegas.

Si bien el suministro de este vital líquido lo tenía garantizado el recinto desde la época almohade, periodo en que se construyeron los caños de Carmona, fue durante los primeros años del dominio cristiano que se sentaron las bases legales respecto al tema hídrico en la urbe hispalense. En el año de 1254 el rey Alfonso X estableció el llamado

\footnotetext{
${ }^{32}$ AGS, CCA, CED, 4, 66, 1

${ }^{33}$ AGS, RGS, LEG, 149804, 73.

${ }^{34}$ AGS, RGS, LEG, 149805, 298.
} 
"Privilegio de los molinos", el único marco legal que existió sobre el tema del agua en los siguientes siglos. $^{35}$

Al momento de elaborar este acuerdo la cantidad de agua que se requería en la ciudad parece no haber sido muy grande (de ahí que fuera suficiente el abastecimiento de dos fuentes), sin embargo, a lo largo de los reinados de Juan II y Enrique IV, diversos actores de la ciudad, principalmente nobles, incrementaron sus demandas de acceso al agua corriente, pues además de representar un elemento de utilidad económica (las mercedes podían ser subarrendadas), implicaba mostrar su cercanía al rey y la posibilidad de contar con jardines y huertas en sus residencias particulares, con lo que poder emular el palacio real. ${ }^{36}$ La situación continuó durante el reinado de Isabel y Fernando, aunque con ellos serían los monasterios y las instituciones tanto religiosas como civiles los principales beneficiarios del agua real. ${ }^{37}$

A la problemática generada por las nuevas mercedes de agua otorgadas por la Corona, se sumaron situaciones como la aparición de tomas clandestinas, la alteración de las medidas señaladas en las mercedes o la falta de mantenimiento de los Caños de Carmona por parte del concejo hispalense, que en conjunto generaban la reducción del caudal de agua que llegaba a la residencia regia, hecho en particular desastroso para los jardines, cocinas, huertas y patios del conjunto edilicio. Esta situación, que ya en 1467 había llamado la atención del bando que apoyaba el reclamo al trono castellano del hermano de Isabel, Alfonso de Castilla, ${ }^{38}$ obligó a los monarcas a tomar cartas en el asunto.

En el año 1479 la reina escribió al concejo de Sevilla y a su alcaide, por la sazón Pedro de Silva, para llamarles la atención respecto a la falta de agua que sufría el palacio real sevillano. Según la carta, el problema radicaba en que, desde Alcalá hasta la puerta de Carmona, diversos particulares tomaban más agua de los Caños de la que se les había otorgado, sin que hubiera vigilancia alguna. Por otro lado, los vecinos de la ciudad incurrían en diversas prácticas que afectaban el suministro de agua de la residencia regia; algunos tomaban una parte de manera furtiva, otros revendían sus mercedes y varios más ampliaban sus marcos de manera ilegal, de suerte tal que, según un documento regio: "la agua que queda para los dichos mis alcaçares es la postrimera, e los otros todos toman primero e los dichos mis alcaçares a la postre, muchos días quedan y están en seco, e non viene a ellos agua alguna, ni a la dicha huerta de la Alcoba." ${ }^{39}$ Otra vez notamos la

\footnotetext{
${ }^{35}$ FERNÁNDEZ CHAVES, 2012, p. 31. En el Privilegio también quedó establecido que el concejo sevillano estaba encargado de dar mantenimiento a los caños, para conocer sobre el mantenimiento de los dichos caños vid MONTES ROMERO-CAMACHO, 2010, p. 55-90, así como NAVARRO SAINZ, 2004, p. 590-596.

${ }^{36}$ Vid DEL VAL VALDIVIESO, 2015, p.78-79; FERNÁNDEZ CHAVES, 2012, p. 325-359.

${ }^{37}$ Como ejemplos se pueden mencionar documentos como: "Carta de merced al monasterio de San Pablo de una blanca de Agua de los caños de Carmona" en CARRIAZO ARROQUIA y CARANDE (eds.), op cit, Tomo V, p. 97; "Carta para que den agua al monasterio de santo domingo", en CARRIAZO ARROQUIA y CARANDE (eds.), op cit, Tomo II, p. 64-65; "Carta de merced del dicho cornado de la dicha agua a la dicha condesa", en CARRIAZO ARROQUIA y CARANDE (eds.), op cit, Tomo IV, p. 76-77; "Carta de merced de un cornado de agua al tesorero Ruy López de Toledo", en CARRIAZO ARROQUIA y CARANDE (eds.), op cit, Tomo IV, p. 233; AGS, CCA, CED, 4, 136, 6; AGS, CCA, CED, 5, 312, 4.

${ }^{38}$ AGS, RGS, LEG, $146712,7$.

39 "Carta de comisión para el asistente e alcayde Pedro Silva. Comisión al asistente y al alcalde de Sevilla a petición de dicha ciudad sobre el perjuicio que ésta dice recibía de ciertas personas que, contra los privilegios de Fernando III el Santo, se aprovechan del agua que por los caños de Carmona ha de abastecer a los alcázares.", CARRIAZO ARROQUIA y CARANDE (eds.), op cit, Tomo II, p.388.
} 
preocupación de la pareja real por contar con una residencia en Sevilla que estuviera en buenas condiciones.

Frente a esta situación, la reina le ordenaba a Diego de Merlo, por entonces asistente de Sevilla, y a Pedro de Silva que formaran una comisión junto con dos o tres miembros del cabildo, para que compararan la situación de ese momento contra las mercedes emitidas por los monarcas anteriores, revisando que todas las tomas tuvieran un documento como garante, así como que los marcos asociados a esas mercedes no hubieran sido alterados de manera unilateral. Para facilitar las pesquisas de la comisión, los oficiales del concejo debían llamar a todos los que tuvieran una merced de agua para revisarla y dar sentencia al respecto. Llama la atención el interés que prestaba la reina a este tema, dado que los miembros de la comisión debían jurar ser imparciales para formar parte de ella.

En caso de que encontraran gente que tomaba el agua de manera ilegal, debían derribar "qualesquier caños e hedifiçios que tengan fechos por donde la toman e echedes e guiedes la dicha agua a la dicha açequia e caños, e pongades pena a las tales personas." ${ }^{40} \mathrm{~A}$ quien fuera descubierto tomando más agua de la permitida "que las redusades al marco de la moneda que corría al tiempo que ouieron las tales merçedes." ${ }^{41}$ La carta también señala que a quien se les descubriera volviéndolo a hacer debía perder para siempre las mercedes que habían recibido. ${ }^{42}$ Por último, indica que sí alguien dentro de Sevilla hacía algún daño a los caños desde la puerta de la ciudad hasta el palacio, las autoridades tenían la facultad de asignar la pena que ellos consideraran justa y que tomaran de sus posesiones lo necesario para reparar el daño.

Es difícil saber si realmente los Alcázares no recibían agua, toda vez que la noticia nos llega desde el ámbito regio. Sin embargo, la presión sobre el concejo en este respecto no parece ser ajena al ambiente político de la ciudad y a la intención de la Corona de restaurar tanto el palacio como el orden social imperante, por eso es revelador que también se remarcara que la carta debía ser pregonada públicamente en plazas y mercados para que todos fueran enterados de tal situación.

No obstante el tono del documento antes reseñado, todo parece indicar que el concejo desobedeció la orden y que la comisión no fue formada, dado que pocos meses después, en enero de 1480, los reyes volvieron a insistir tanto al alcaide como al Asistente de Sevilla sobre la necesidad de llevar a cabo la investigación, por lo que les mandaban que hicieran jurar a los dos o tres veinticuatros de la comisión frente al escribano de los Alcázares, Alvar García de Ciudad Real, y llevaran a cabo la investigación. ${ }^{43}$

Al final la comisión se logró crear, sin embargo, no obtuvo resultados satisfactorios. Otra misiva de la reina al concejo sevillano con fecha de diciembre de 1480 señala que si bien las personas nombradas para llevar a cabo la comisión de las aguas habían llamado a presentarse a todos los que tuvieran mercedes para evaluarlas, pocos lo habían hecho. Por lo anterior, la reina señalaba que:

del día con que esta mi carta fuerdes requeridos e fuere mostrada en vuestro cabildo e pregonada públicamente pro las plaças e mercados e otros lugares acostunbrados desa dicha çibdad, fasta veynte días primeros siguientes, los quales vos do e asigno por todos plazos e

\footnotetext{
${ }^{40}$ Ibídem.

${ }^{41}$ Ibídem.

${ }^{42}$ Ibídem.

43 "Sobrecarta en razón de la comisión de los cannos del agua" en CARRIAZO ARROQUIA y CARANDE (eds.), op cit, Tomo III, p. 38.
} 
término perentorio, vengays y parescades ante los dichos juezes, e mostredes ante ellos todos e qualesquier títulos e merçedes que de la dicha agua teneys. ${ }^{44}$

Como amenaza, señalaba que los oficiales tenían la capacidad de cerrar las tomas de agua de aquellos que no acudieran a presentar los documentos que probaran el otorgamiento real, también se mencionaba que si los mismos jueces no podían acudir a cumplir con el mandato se permitía que su lugar fuera tomado por otros, lo cual me parece que demuestra el profundo interés de la Corona en que se atendiera el problema.

No queda claro si la advertencia de la reina tuvo efecto o no, puesto que no se encontraron documentos de los siguientes dieciséis años que hagan referencia al tema. Sin embargo, en el año de 1496, durante una estancia de los Reyes Católicos en Tortosa, sabemos que el agua volvió a estar en el centro de la atención regia, ya que tenemos una carta enviada a Juan Ome, a Álvaro de Portugal, a Lope de Agréda, veinticuatro de Sevilla, y a Francisco Pinelo, jurado de la ciudad. En ella, podemos encontrar inserta la carta sobre la investigación de las concesiones de agua escrita en 1479 así como un señalamiento de los monarcas respecto al mismo problema. También mandaban a los receptores de la carta a llevar a cabo la misma investigación, al parecer el tema no había sido solucionado en las ocasiones anteriores. $^{45}$

\section{Conclusión}

Hasta aquí será evidente que durante el reinado de Isabel I de Castilla y Fernando II de Aragón se generaron varios conflictos entre el concejo de la ciudad y la Corona por las prerrogativas y los derechos que tenía el palacio hispalense dentro del ámbito urbano. Sin duda, el proyecto de recuperación que los monarcas querían llevar a cabo era uno de los motivos más importantes para enfrascarse en esas disputas con el gobierno concejil, en varios de los documentos aquí analizados se puede hallar que la razón esgrimida para demandar que las mencionadas prerrogativas fueran respetadas y acatadas son los daños que sufrían o sufrirían los alcázares.

$\mathrm{Y}$ es que como hemos visto las prerrogativas del palacio tenían un papel fundamental puesto que gracias a ellas se podía pagar a los oficiales sus salarios, contar con mano de obra especializada en el mantenimiento de la fábrica existente o en la construcción de nuevos elementos arquitectónicos, así como contar con agua en las huertas, jardines, patios y cocinas, que era un recurso esencial para el funcionamiento de la residencia real y para la demostración de su poder por medio de la arquitectura.

En este orden de ideas, no es mera coincidencia que, al tiempo que debieron empezar las obras de reparación encomendadas a Francisco Ramírez de Madrid, aparezcan una gran cantidad de reclamos provenientes del ámbito real que tenían por objetivo hacer que se guardasen los derechos con los que el palacio y sus trabajadores contaban dentro de la urbe hispalense.

A través de los pleitos aquí abordados también se pueden evidenciar de manera clara las dificultades que los monarcas y el entorno real tuvieron que afrontar para poder llevar a cabo su proyecto restaurador; no sólo había que pacificar a los nobles de la región,

\footnotetext{
44 "Carta sobre el agua que va a los alcazares." en CARRIAZO ARROQUIA y CARANDE (eds.), op cit, Tomo III, p. 138.

45 "Carta sobre el agua de los cannos.", en FERNÁNDEZ GÓMEZ, OSTOS SALCEDO y PARDO RODRÍGUEZ (eds.), 1997, tomo VII, p. 387-390.
} 
reparar de manera urgente un serie de edificios con graves daños y que ya no se amoldaban a las nuevas necesidades de la corte, sino que también era necesario confrontar a las autoridades locales para que cumplieran con sus obligaciones. Queda la duda de si este mismo fenómeno tuvo lugar en otras localidades castellanas, como Córdoba, donde se llevaron a cabo obras similares a las del Alcázar de Sevilla.

En este sentido, más allá de si las demandas se resolvieron de manera efectiva o no, conviene recalcar la aparente dificultad que tuvo la Corona para hacer valer sus derechos dentro del entorno urbano hispalense, cosa patente en los tres ámbitos aquí señalados. La repetición de sendas llamadas de atención al concejo sevillano para que se respetaran los derechos sirve para mostrar las dificultades que enfrentó el gran proyecto de fortalecimiento de la institución monárquica que tenían los Reyes Católicos.

Sin embargo, también es interesante notar que frente a la falta de acatamiento por parte de las autoridades concejiles y la aparente incapacidad de la Corona para imponer su completa voluntad, los diversos personajes involucrados en los pleitos se vieron obligados a solucionar sus diferencias por medio de negociaciones, debiendo ceder en ciertos momentos. Los ejemplos aquí presentados hacen evidente que en este respecto tuvo un papel central el alcaide del Alcázar. Éste, como representante de la voluntad regia in situ, debió muchas veces negociar y llegar a acuerdos con sus contrapartes sevillanas, para lo que su derecho a voz y voto dentro del concejo por su calidad de veinticuatro debió ser un elemento que suponemos fue muy útil.

De su papel mediador podríamos mencionar como el caso más evidente, el acuerdo al que llegaron en 1479 Pedro de Silva y el concejo de la ciudad en lo referente al número de los trabajadores francos. Sin embargo, no hay que olvidar que, según las disposiciones reales, la persona del alcaide también debía jugar un papel protagónico en la investigación de las faltas y quebrantamientos de los derechos del alcázar en el tema del suministro de agua o de los diezmos del ladrillo o la teja.

Esta investigación hace evidente la conveniencia de investigar de manera más profunda el actuar de los alcaides y sus lugartenientes durante este periodo, abordando la forma en que sus intereses se relacionaban y mezclaban con los intereses de los monarcas y los de los grupos de poder de la ciudad, así como la forma en que se llevaron a cabo las negociaciones. Sin embargo, dicha investigación requeriría analizar y comparar los textos producidos por la Corona, con los procedentes de otros actores como el mismo cabildo, los nobles de la ciudad o la Iglesia.

Los documentos aquí reseñados también permiten profundizar en la compleja relación que se estableció entre la residencia regia y su entorno urbano, la cual no se reducía a los momentos en que los monarcas estuvieron aposentados o a los eventos que ahí ocurrían. Se puede observar que además de haber sido la residencia real, la representación de la institución monárquica y un incontestable centro de poder político, los Reales Alcázares tenían una influencia muy fuerte en temas como el suministro de agua, la producción económica o la distribución de las contribuciones dentro de la sociedad hispalense. No obstante, esta influencia podía ser sujeta a negociación. A juzgar por los documentos analizados aquí, esta negociación debió volverse más tensa y conflictiva debido al interés de los Reyes Católicos por recuperar el sitio real sevillano. 


\section{REFERENCIAS BIBLIOGRÁFICAS}

ALMAGRO GORBEA, Antonio, "La planta alta del palacio de Pedro I en el Alcázar de Sevilla", Anuario del Departamento de Historia y Teoría del Arte, vol. 27, 2015, pp. 69115.

185.

CARRIAZO ARROQUIA, Juan de Mata, y CARANDE, Ramón (eds.), El tumbo de los Reyes Católicos del Concejo de Sevilla, Sevilla, Fondo para fomento de la investigación en la Universidad; Ayuntamiento de Sevilla, 1968-1971, vol. 1-5.

CASTILLO OREJA, Miguel Ángel, "La conservación de un valioso legado: La rehabilitación de los alcázares reales en la política constructiva de los Reyes Católicos" en Miguel Ángel Castillo Oreja (ed.), Los alcázares reales. Vigencia de los modelos tradicionales en la arquitectura áulica, Madrid, Fundación BBVA, A. Machado Libros, 2001, p. 99-128.

COLlANTES DE TERÁN SÁNCHEZ, Antonio, Sevilla en la Baja Edad Media. La ciudad y sus hombres, $2^{\mathrm{a}}$ ed., Sevilla, Servicio de Publicaciones del Excmo. Ayuntamiento de Sevilla, 1984.

Cortes de los antiguos reinos de León y Castilla, publicadas por la Real Academia de la Historia, Madrid, Establecimiento tipográfico de los sucesores de Rivadeneyra, impresores de la Casa Real, 1882.

DEL VAL VALDIVIESO, María Isabel, "Política urbana y percepción de los recursos hídricos en la Castilla bajomedieval”, Minius. Historia, arte e xeografía, núm. 23, 2015, p.78-79.

DOMÍNGUEZ CASAS, Rafael, Arte y etiqueta de los Reyes Católicos: artistas, residencias, jardines y bosques, Madrid, Alpuerto, 1993.

FERNÁNDEZ AGUILERA, Sebastián, "Origen del Palacio de Pedro I en el Alcázar de Sevilla: El mirador hoy llamado de los Reyes Católicos", Archivo español de arte, LXXXVIII, 352, octubre-diciembre 2015, p.331-348.

FERNÁNDEZ CHAVES, Manuel, Política y administración del abastecimiento de agua en Sevilla durante la Edad Moderna, Sevilla, Diputación Provincial de Sevilla, 2012.

-----------, "El papel de los nobles y los conversos en la difusión del agua de pie”, en María Isabel del Val Valdivieso y Juan Antonio Bonachía Hernández (coords.), Agua y sociedad en la Edad Media hispana, Granada, Universidad de Granada, 2012, p. 324-325.

FERNÁNDEZ GÓMEZ, Marcos (ed.), El Alcázar de Sevilla en el reinado de los Reyes Católicos. Las cuentas del obrero mayor Francisco de Madrid, Sevilla, Patronato del Real Alcázar y de la Casa Consistorial de Sevilla, 2011, p. 35-48.

FERNÁNDEZ GÓMEZ, Marcos, OSTOS SALCEDO, Pilar y PARDO RODRÍGUEZ, María Luisa (eds.), El tumbo de los Reyes Católicos del Concejo de Sevilla, Madrid, Fundación Ramón Aceves, 1997, vol. 6- 13.

GESTOSO, José, Los Reyes Católicos en Sevilla: (1477-1478), Sevilla, Imprenta de la Revista de los Tribunales, 1891. 
---------------, Sevilla monumental y artística: historia y descripción de todos los edificios notables, religiosos y civiles que existen actualmente en esta ciudad y notica de las preciosidades artísticas y arqueológicas que en ellos se conservan, Tomo I, Sevilla, El Conservador, 1889-1890.

LADERO QUESADA, Miguel Ángel. "Los alcázares reales en la Baja Edad Media castellana: Política y sociedad”, en Miguel Ángel Castillo Oreja (ed.), Los alcázares reales. Vigencia de los modelos tradicionales en la arquitectura áulica, Madrid, Fundación BBVA, A. Machado Libros, 2001, p. 99-128.

MARÍN FIDALGO, Ana, El Alcázar de Sevilla bajo los Austrias, Sevilla, Guadalquivir, 1990, Tomo 1.

MONTES ROMERO-CAMACHO, Isabel, "El abastecimiento de agua en la Sevilla bajomedieval: Los moros cañeros" en Beatriz Arízaga Bolumburu, Jesús Ángel Solórzano Telechea (coords.), Construir la ciudad en la Edad Media, España, Instituto de Estudios Riojanos, 2010, p. 55-90.

MORALES, Alfredo J., y SERRERA, Juan Manuel, "Obras en los Reales Alcázares de Sevilla en tiempos de los Reyes Católicos", Laboratorio de Arte, 12, 1999, pp. 69-77.

MORALES, Alfredo J., "Los Reyes Católicos y el Alcázar de Sevilla. De la restauración a la renovación" en Castillo Oreja, Miguel Ángel (ed.), Los alcázares reales. Vigencia de los modelos tradicionales en la arquitectura áulica, Madrid, Fundación BBVA, A. Machado Libros, 2001, p.129-144.

MORALES, Alfredo J., "Los Reyes Católicos, el Alcázar de Sevilla y su obrero mayor Francisco Ramírez de Madrid" en Marcos Fernández Gómez, (ed.), El Alcázar de Sevilla en el reinado de los Reyes Católicos. Las cuentas del obrero mayor Francisco de Madrid, Sevilla, Patronato del Real Alcázar y de la Casa Consistorial de Sevilla, 2011, p. 35-48.

NAVARRO SAINZ, José María, El Concejo de Sevilla en el reinado de Isabel I (14741504). Tesis doctoral en formato electrónico, Sevilla, Universidad de Sevilla, 2004, https://idus.us.es/xmlui/handle/11441/1521. 